\title{
Peak Temperature Correlation and Temperature Distribution during Joining of AZ80A Mg Alloy by FSW - A Numerical and Experimental Investigation
}

\author{
P. Sevvel1, ${ }^{*}-$ S.D. Dhanesh Babu ${ }^{2}-$ R. Senthil Kumar ${ }^{1}$ \\ ${ }^{1}$ S.A. Engineering College, Department of Mechanical Engineering, Chennai, India \\ ${ }^{2}$ St. Joseph College of Engineering, Department of Mechanical Engineering, Sriperumbudur, India
}

A quadratic equation has been developed based on experimental measurements to estimate the peak temperature in the friction stir welding (FSW)process during the joining of AZ8OA Mg alloys. The numerical simulation of the FSW process was performed by employing COMSOL software to predict and calculate the distribution of temperature on the various regions of the parent metal and the welded joints. The predicted and finite element analysis (FEA) simulating the results of the distribution of peak temperatures were found to be consistent with the experimental values. In addition to this, a parametric experimental investigation was conducted to identify the most influential process parameter that plays a significant role in the peak temperature distribution during FSW of AZ80A Mg alloy. Linear contributions by the input process parameters of FSW, namely, traversing speed, rotating tool speed and axial force on the peak temperature were observed to be 32.82 $\%, 41.65 \%$ and $21.76 \%$, respectively.

Keywords: peak temperature, AZ80A Mg alloy, process parameter, friction stir welding, tool pin profile

\section{Highlights}

- An investigational analysis during joining of AZ8OA Mg alloy was carried out to formulate a correlation to analyse the generation of peak temperature.

- The domination and significance of several parameters of FSW process on peak temperature during the joining of AZ80A alloy was investigated experimentally and numerically.

- A three-dimensional steady-state model for heat-transfer in a movable type coordinate was modelled and simulated to visualize the temperature distribution in the parent metal.

- The significance test of the predicted model fit for maximum temperature was performed using Minitab tool based on analysis of variance (ANOVA), and it was observed that the developed model was perfectly ideal, as the value of $F$ was quite larger and Prob $>F$ value was lower by 0.05 .

- It was inferred that performing the FSW of AZ80A Mg alloys at the optimized combination of higher speeds of tool rotation, with the FSW tool traversing at low speeds and by applying larger values of the axial load will result in the generation of ideal peak temperature, which will eventually contribute to perfect bonding between the AZ80A Mg alloy plates to be welded, thereby resulting in sound quality weldments.

\section{O INTRODUCTION}

As one of the earth's lightest metal alloys, Mg alloys are widely preferred for a variety of applications, in particular for aerospace, structural, automotive, electronics, and shipbuilding sectors [1] and [2]. The promising characteristic features of $\mathrm{Mg}$ alloys, in particular, AZ80A Mg alloy, includes tremendous strength-to-weight proportions, exceptional machinability, outstanding sound-absorbing potential, uncomplicated recyclability, and excellent machinability have attracted and gained the attraction of numerous researchers, in recent decades [3] and [4]. Concurrently, joining magnesium alloys is a tough task, especially when carried out by employing conventional joining processes, which is mainly due to their high thermal potential, which leads to undesirable features, including unrefined microstructure, porosity, relentless fracture, soaring residual stress, etc., in the joints obtained by employing conventional techniques [5] and [6].

A solid-state category of joining process like friction stir welding (FSW) is effective in eliminating those various defects associated with the employment of conventional welding processes employed for joining of AZ80A Mg alloys [7] and [8]. During the process of FSW, a uniquely designed tool with shoulder-and-pin arrangement is plunged (at a desirable rotating speed) exactly at the centre of the joining butt edges of the two similar or dissimilar plates to be joined and is made to traverse continuously along the line of fabrication, as illustrated in the Fig. 1. During this joining process, heat is generated due to the friction between the tool shoulder surface and the workpiece surface. Due to this generated frictional heat, the material of the flat plates (kept for joining) 
is softened and reaches the plasticized state. The flow of these softened plasticized materials to the other side occurs due to the stirring action of the tool pin and impact of traversing tool shoulder. As a result, the mixing of the plasticized materials happens on both sides of the line of the joint, while the tool traverses along this joint line and thereby leading to the formation of a joint, without melting the base metals. The employed tool is then slowed gradually from the line of joint; next, the workpieces are allowed to cool down and thus, a solid phase of bonding is attained between the workpieces [9] to [11].

Temperature generation and its distribution over the various regions during the FSW process have an invigorating impact on the microstructural features and mechanical features of the fabricated welds [12]. For example, a flow-segregated deformation model was proposed by Arbegast [13] to depict the circumstances during which the formation of volumetric defects occurs during the joining of metals by the FSW process. It was observed that the disproportionate flow of plasticized material arising due to generation of high FSW processing temperature results in the formation of flash, the collapse of stir zone, etc. Padmanaban et al. [14] devised an analytical procedure to anticipate the generation and distribution of temperature and flow of the plasticized metal during FSW of AA7075 and AA2024 Al alloys. It was recorded that the level of temperature escalates with the rise in the speed of rotation of that cylindrical tool and with the increase in the diameter of that cylindrical tool's shoulder.

A 3-D-based model for the transfer of heat during the process of FSW was put forward by Song and Kovacevic [15]. The equations of control were solved using the methodology of finite difference, and an intermittent mesh of the grid was used to calculate the temperature levels. Chao et al. [16] devised the transfer of heat taking place during the FSW process into a constant state horizon value-based scenario and calculated the temperature levels on the FSW tool and workpiece. This analysis recorded that nearly 90 $\%$ to $94 \%$ of the generated heat is transferred to the workpiece, and remaining heat stays with the tool.

Even though, an essential need for deriving and implementing suitable strategies for control of temperature exists in order to fabricate sound, high quality, defect-free welds, there is no consistent conclusion on the relationship between the welding parameters with the peak temperature. In this study, the domination and significance of several parameters of FSW process on peak temperature during joining of AZ80A alloy were investigated experimentally and numerically. $T_{\max }$ correlation for AZ80A magnesium alloy was developed, for the first time, to accurately predict the peak temperature in the FSW process using the Minitab tool. The distribution of temperature on the various regions of the workpiece (AZ80A Mg alloy) was simulated by a steady-state heat transfer numerical approach using Comsol software. The predicted and FEA simulated peak temperatures were validated against experimental temperature measurements. Finally, a numerical parametric study was conducted taking into consideration the various parameters namely welding speed, axial load, and rotational tool speed to identify the most influential parameter affecting the peak temperature in the FSW process.

\section{EXPERIMENTAL}

\subsection{Material, Machine, Tool, and Experimental Setup}

The wrought alloy of magnesium AZ80A (flat plates of $5 \mathrm{~mm}$ thickness) was the metal of examination in this experimental and numerical investigation. The chemical composition of the investigated AZ80A Mg flat plates was found to contain various elements, namely $\mathrm{Al}, \mathrm{Mn}, \mathrm{Cu}, \mathrm{Ni}, \mathrm{Zn}$, etc. in the proportions of $7.85 \% \mathrm{Al}, 0.37 \% \mathrm{Mn}, 0.052 \% \mathrm{Cu}, 0.51 \% \mathrm{Fe}, 0.70 \%$ $\mathrm{Zn}, 0.049 \% \mathrm{Ni}, 0.12 \% \mathrm{Si}$ and the remaining element was $\mathrm{Mg}$. The strength of this alloy was observed to be in the value of $330 \mathrm{MPa}$ (Tensile), $230 \mathrm{MPa}$ (Yield) and $11 \%$ (elongation).

The joining (butt joint) of the flat plates (thickness: $5 \mathrm{~mm}$ ) of parent metal (AZ80A Mg) was carried out by using a congenitally contrived, pseudo-automatic nature of FSW machine, enclosed with a motor spindle of $5 \mathrm{~kW}$ capacity, together with a $400 \mathrm{~mm} \times 810 \mathrm{~mm}$ table, which can traverse in three different axes at a dimension of $510 \mathrm{~mm}$ (longitudinally), $400 \mathrm{~mm}$ (horizontally and vertically).

The FSW tool employed in this experimental work was fabricated using the M35 grade highspeed steel, and it has a cylindrical shaped stepped shoulder (outer shoulder diameter of $20 \mathrm{~mm}$ and 15 $\mathrm{mm}$ diameter inner shoulder), along with a tapered pin profile (4.75 $\mathrm{mm}$ length). The photographic illustration of the different views of the tool used in this experimental and numerical investigation is shown in Fig. 1. Thermocouples made of Al-Cr wire were used to measure the workpiece temperature during this joining of AZ80A Mg alloy by the employment of the FSW process.

The adopted schematic arrangement and installation of the thermocouples at various locations 
on the AZ80A (parent metal) $\mathrm{Mg}$ alloy surface is illustrated in Fig. 2. Temperature measurement was taken in three categories viz.; a) top side $10 \mathrm{~mm}$ offset from the axial line, b) top side transverse axis, and c) bottom side axial line.

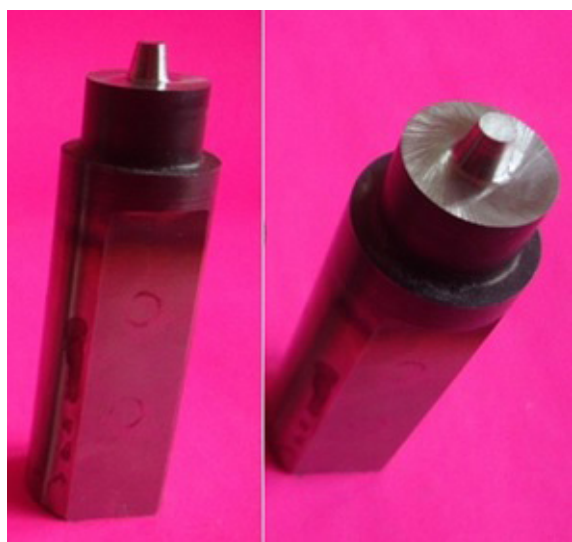

Fig. 1. Photographs of the different views of the tool used in this experimental and numerical investigation

\subsection{Experimental Design Scheme}

The impact of the several parameters on the peak temperature $\left(T_{\max }\right)$ during the joining of AZ80A $\mathrm{Mg}$ alloy flat plates employing FSW process was analysed by the adoption of a three-factor and threelevel investigational design (full factorial-based) concept. The details of these influential parameters together with their coded ( $F$ axial force; $F_{d}$ tool's speed of traverse and $S$ tool's rotational speed) and corresponding realistic investigational values are elaborated in Table 1.

Table 1. Description of influential parameters (taken into account) together with their coded and corresponding investigational values during joining of AZ80A Mg alloy by FSW

\begin{tabular}{lccccc}
\hline \multirow{2}{*}{ Significant criterion } & \multirow{2}{*}{ Denotation } & \multirow{2}{*}{ Unit } & \multicolumn{4}{c}{ Coded levels } \\
\cline { 3 - 6 } & & & 1 & 0 & -1 \\
\hline Traversing speed & $F_{d}$ & $\mathrm{~mm} / \mathrm{s}$ & 3 & 1.75 & 0.5 \\
\hline Force & $F$ & $\mathrm{kN}$ & 5 & 4 & 3 \\
\hline Tool rotational speed & $S$ & $\mathrm{rpm}$ & 1000 & 750 & 500 \\
\hline
\end{tabular}

A $2^{\text {nd }}$ order equation of polynomial nature was employed to fit the results of the investigational work. The proposed equation interprets the impact and role of the above-mentioned influential parameters and their interplay on the response variable (namely peak temperature). The generalized structure of the developed model is described, as shown below:

$$
\begin{aligned}
T & =K_{0}+K_{1} A+K_{2} B+K_{3} C+K_{12} A B+K_{13} A C+ \\
& +K_{23} B C+K_{11} A^{2}+K_{22} B^{2}+K_{33} C^{2}
\end{aligned}
$$

where the anticipated response is indicated by $T$, model constant by $K_{0}$, linear coefficients by $K_{2}$, $K_{1}, K_{3}$, cross-product coefficients by $K_{13}, K_{12}, K_{23}$, quadraticcoefficientsby $K_{22}, K_{11}, K_{33}$. The effectiveness of the model was analysed using the Minitab Software

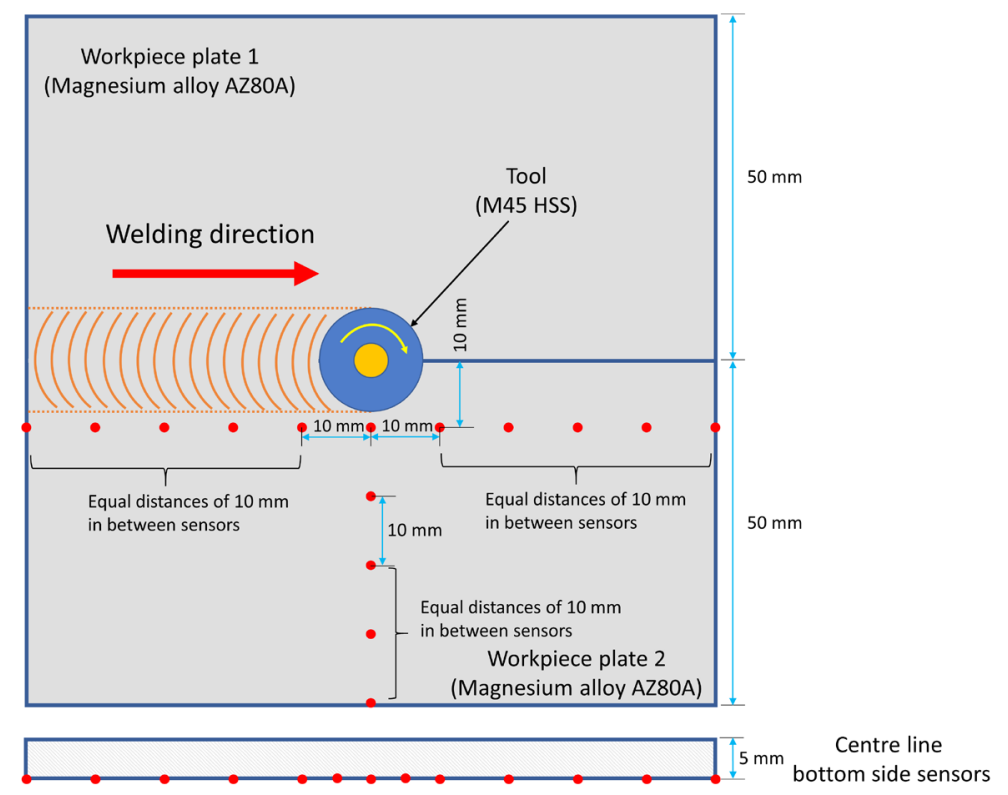

Fig. 2. Schematic view of the arrangement of the thermocouples at various locations on AZ80A Mg alloy flat plates surface 
and by the employment of the analysis of variance (ANOVA).

\subsection{FEA Modeling of the FSW Process}

Differential equation-based issues can be tackled by approximating the issue using a numeric strategy [17] and [18]. In this experimental investigation, the proposed analytical model for joining AZ80A $\mathrm{Mg}$ alloy employing an FSW tool (having a stepped cylindrical shoulder and tapered pin geometry) was formulated by applying the Comsol Multiphysics heat transfer segment. Statistical modelling is the partition and segregation of a geometrical region into limited cardinal points and rudimental volumes [19] and [20]. In this proposed model, a precise estimation of the administering horizon conditions influencing every network point and their adjoining points were also specified. Results were also derived for these structures of equations, culminating from the abovementioned approximations. It can be visualized that the geometrical domain is symmetrical about the weld line. Hence, it is acceptable to model and conceptualize any of the flat plates of the base metal during their FSW. The dimension of the AZ80A Mg alloy flat plates welded in this experimental work is 50 $\mathrm{mm}$ (width) $\times 100 \mathrm{~mm}$ (length). The flat plates of the parent metal (AZ80A Mg alloy) were attached with two perpetual dominions along the $X$-direction. The obtained computational domain through FEA analysis for the base material on our investigational work, namely, AZ80A Mg alloy is graphically illustrated in Fig. 3.

\subsection{Governing Equations and Numerical Scheme}

Usually, during friction stir welding, the travel of the FSW tool is along the line of the joint of the weld. The proposed models by various researchers were proven to have some complications, as they have considered the FSW tool as a movable source of heat [21] and [22]. However, in the present experimental work, a lateral concept of the system of movable coordinates was employed, and the coordinates were fixed at the axis of the FSW tool. Due to this transfiguration of coordinates, the problem of transfer of heat is converted into static conduction-convection scenario, which is unequivocal to the proposed model. Moreover, this strategy of considering a movable type coordinate in this proposed model eliminates the need for modelling the processes taking place around the region of the FSW tool pin, thereby making this proposed model simplified and effective.

The equation representing the amount of transfer of heat taking place on the parent metal of our experimental investigation (i.e., AZ80A Mg alloy) in a movable type coordinate is,

$$
\rho C_{p} \mu \cdot \nabla T+\nabla \cdot(-k T \nabla)=Q,
$$

where the temperature being generated is indicated by $T$, the capacity of heat by $C_{p}$, the density being indicated by $\rho$, the conductivity of heat by $K$, and the travelling speed of tool by $\mu$.

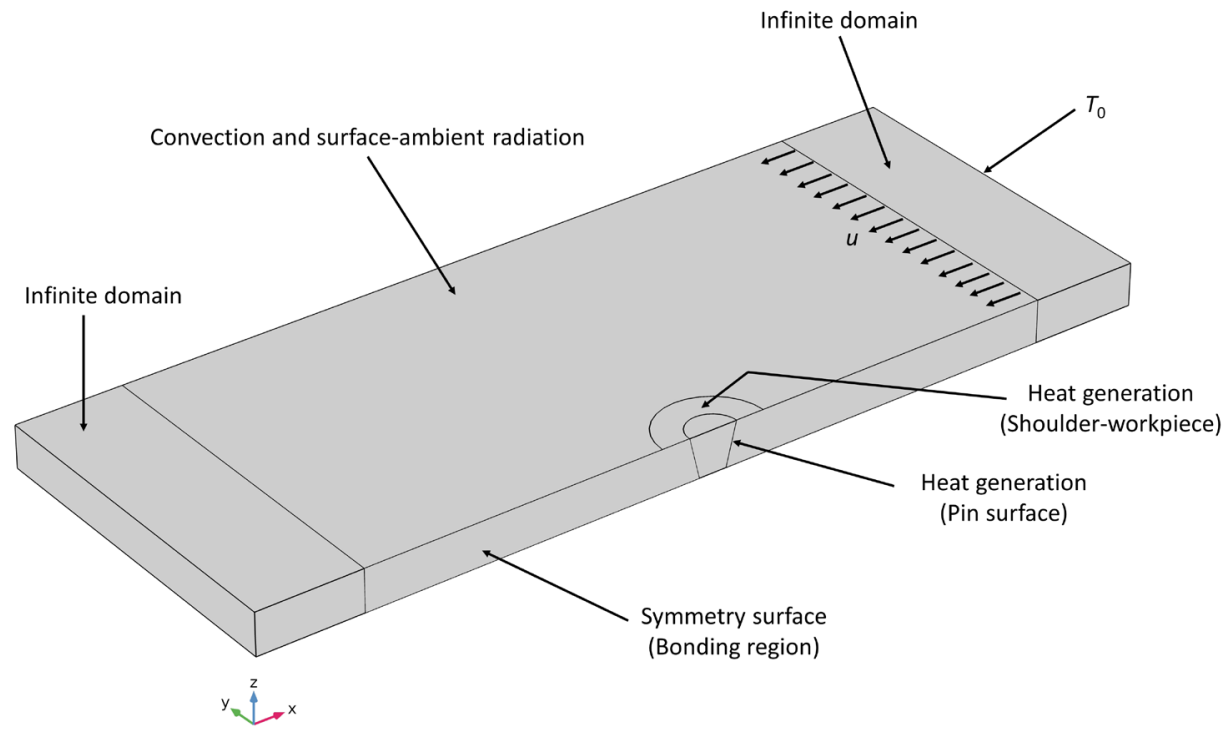

Fig. 3. Generated model geometry for FSW simulation 
Table 2. Various temperature-dependent properties of AZ80A Mg alloy considered in this experimental work

\begin{tabular}{lcccccccc}
\hline Temperature $\left[{ }^{\circ} \mathrm{C}\right]$ & 20 & 50 & 100 & 150 & 200 & 250 & 300 & 350 \\
\hline Thermal conductivity $[\mathrm{W} /(\mathrm{m} \cdot \mathrm{K})]$ & 59.2 & 63.3 & 68.2 & 73.4 & 77.3 & 82.1 & 92.9 & 98.9 \\
\hline Specific heat $[\mathrm{J} /(\mathrm{kg} \cdot \mathrm{K})]$ & 0.975 & 1.032 & 1.076 & 1.105 & 1.125 & 1.141 & 1.155 & 1.165 \\
\hline Density $\left[\mathrm{kg} / \mathrm{m}^{3}\right]$ & 1806 & 1801 & 1793 & 1786 & 1778 & 1770 & 1763 & 1755 \\
\hline
\end{tabular}

Likewise, the equation that governs the generation of heat in the region of interaction of the shoulder of the FSW tool and the parent metal is as follows:

$$
Q_{\text {shou }}=2 / 3 \pi \omega \tau_{\text {con }}\left(R^{3}{ }_{\text {shou }}-R^{3}{ }_{\text {pin, } \max }\right),
$$

where the generation of heat in the shoulder of the FSW tool is indicated by $Q_{\text {shou }} \omega$ represents the angular rotational speed of the FSW tool, contact shear stress by $\tau_{c o n}$, the radius of the FSW tool shoulder being indicated by $R_{\text {shou }}$ and $R_{p i n, \max }$ represents the maximum radius of the profile of tool pin.

The probe of the employed tool consists of a taper cylindrical surface with a bottom radius of $R_{\text {pin,min }}$, top radius $R_{p i n \text {, max }}$ and probe height $H_{p i n}$. The heat generation equation for the profile of FSW tool pin is,

$$
Q_{p i n}=\frac{\pi \omega \tau_{c o n}}{2} \cdot \frac{H_{p i n}}{\cos \alpha}\left(R_{p i n, \text { max }}+R_{p i n, \text { min }}\right)^{2},
$$

where $Q_{p i n}$ indicates the amount of generated heat in the pin of the tool, the height of the tool pin being indicated by $H_{p i n}$ and $R_{p i n, \text { min }}$ represents the maximum radius of the profile of tool pin.

The topmost and bottom portions of the parent metal experience some heat loss, and this happens mainly due to surface to circling radiation, convection, etc. The interrelated equations defining the flux of heat of these regions are mentioned below:

$$
\begin{gathered}
Q_{u p}=h_{\text {up }}\left(T_{0}-T\right)+\varepsilon \cdot \sigma \cdot\left(T^{4}{ }_{a m b}-T^{4}\right), \\
Q_{\text {down }}=h_{\text {down }}\left(T_{0}-T\right)+\varepsilon \cdot \sigma \cdot\left(T^{4}{ }_{a m b}-T^{4}\right),
\end{gathered}
$$

where the flux of heat on the upper side of base metal flat plates (in $\mathrm{W} / \mathrm{m}^{2}$ ) by $Q_{u p}$, the flux of heat on the upper side of base metal flat plates (in $\mathrm{W} / \mathrm{m}^{2}$ ) by $Q_{\text {down }}$, the temperature reference (in Kelvin) is represented as $T_{0}$, the surface temperature of base metal flat plates by $T$ (in Kelvin), surface emissivity by $\varepsilon$, the Stefan-Boltzmann constant by $\sigma$, the ambient temperature of air (in Kelvin) by $T_{a m b}$ and the transfer of heat coefficients of natural convection are indicated by $h_{\text {down }}$ and $h_{u p}$. In this investigational analysis, the transfer of heat coefficients for the topside was considered to be $6.25 \mathrm{~W} /\left(\mathrm{m}^{2} \mathrm{~K}\right)$ and 12.25 $\mathrm{W} /\left(\mathrm{m}^{2} \mathrm{~K}\right)$ for the bottom-and topside of the workpiece, respectively. The various properties of the parent metal, i.e., Mg alloy (AZ80A), which are taken into account in this experimental analysis for framing the proposed model are described in Table 2.

Similarly, Table 3 describes the various properties of the material used for fabricating the FSW tool (i.e., HSS M35 Grade) employed in this experimental work, for framing the proposed model. From the knowledge gained from the literature survey, it has been observed that for attaining precise results, more grid nodes have to be placed around the surrounding region of the employed tool pin. This is mainly because the range and magnitude of the tool pin profile surface are very much less when compared with that of the workpiece surface. The diagrammatic illustration of the placing of innumerable grid nodes around the region of the FSW tool pin, through the generation of non-uniform mesh, shown in Fig. 4.

Table 3. Various properties of FSW tool material (M35 Grade HSS) considered framing the proposed model

\begin{tabular}{lc}
\hline Characteristics & Value \\
\hline Poisson's ratio & 0.28 \\
\hline Specific heat $[\mathrm{J} /(\mathrm{kg} \cdot \mathrm{K})]$ & 465 \\
\hline Density $\left[\mathrm{kg} / \mathrm{m}^{3}\right]$ & 8140 \\
\hline Thermal conductivity $[\mathrm{W} /(\mathrm{m} \cdot \mathrm{K})]$ & 26 \\
\hline Young's modulus $[\mathrm{GPa}]$ & 207 \\
\hline
\end{tabular}

Table 4. Description of the various essential parameters, including the size of the mesh required for the generation of the mesh in the proposed model

\begin{tabular}{lc}
\hline Description of parameter & Value \\
\hline No. of elements & 35100 \\
\hline Ultimate size of the elements & $2.5 \mathrm{~mm}$ \\
\hline Curvature factor & 0.2 \\
\hline Superlative growth rate of elements & 1.3 \\
\hline Minimal size of the elements & 0.026 \\
\hline
\end{tabular}

Table 4 portrays in detail the various essential parameters, including the size of the mesh required for the generation of the mesh in the proposed model. The mathematical models relevant to the transfer of heat taking place due to radiation; convection and conduction are developed using the steady-state transfer of heat, based on the interface of solids. During the computation process, if the estimated temperature approaches the point of melting of the 


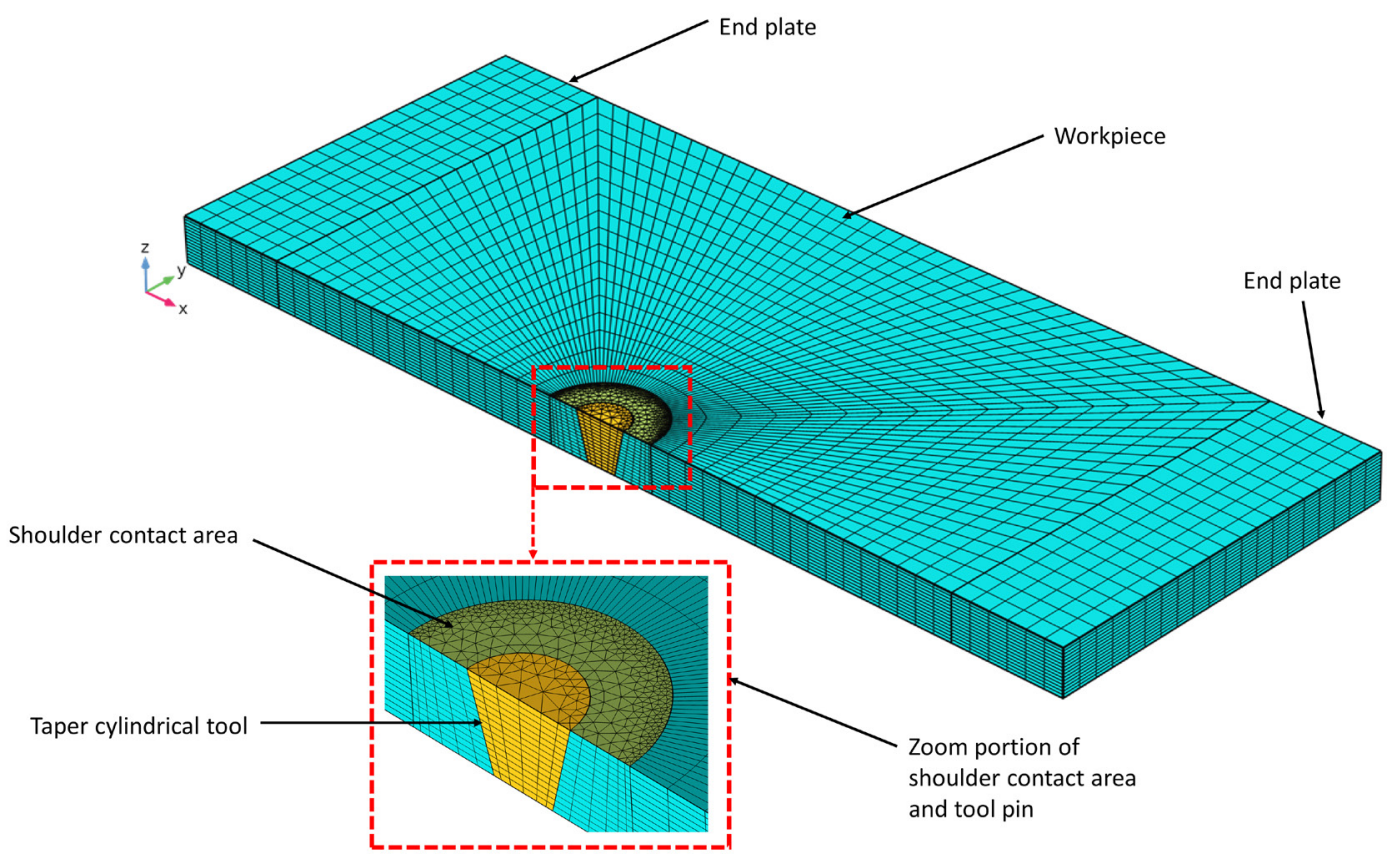

Fig. 4. Generated model geometry for FSW simulation Illustration of the placing of innumerable grid nodes around the region of the FSW tool pin, through the generation of non - uniform mesh

investigating material, then the input of heat produced from the tool is modified to zero.

In this experimental work, the melting point of the base metal is lower, when compared with that of the amount of frictional heat achieved between the workpiece surface and tool. As a result, the proposed model has been framed in such a way that the generation of frictional heat is adjusted to the value of zero, whenever the simulation temperature indicates higher values or values equivalent to the melting point of the parent metal. More simply, it can be written as,

$$
q=0 ; \quad\left(T \geq T_{\text {melt }}\right) .
$$

\section{RESULTS AND DISCUSSIONS}

In this experimental and numerical analysis, 30 experimental runs (inclusive of 3 centre point experiments of control) were performed. The various measurement values obtained from these experiments were employed to frame the analytical model, which represents the peak temperature as the FSW process respond to the in constants. The values of the peak temperature measured during the experimental analysis, along with the predicted and FEA simulated values, are described in Table 5. The actual model equation for predicting the peak temperature $\left(T_{\max }\right)$ of the FSW magnesium alloy AZ80A is given in Eq. (8).

$$
\begin{aligned}
T= & 111.2+0.562 \times \text { Speed }+90.7 \times \text { Force }- \\
& -125.0 \times \text { Feed }-0.000229 \times \text { Speed } \times \text { Speed }- \\
& -6.50 \times \text { Force } \times \text { Force }+12.16 \text { Feed } \times \text { Feed }- \\
& -0.0007 \times \text { Speed } \times \text { Force }+ \\
& +0.02373 \times \text { Speed } \times \text { Feed }+ \\
& +4.73 \times \text { Force } \times \text { Feed } .
\end{aligned}
$$

\subsection{Experimental Validation of $T_{\max }$}

It has been observed that the variations between the predicted correlation and the obtained actual values and the simulated FEA values are neutral and comparably small. The simulated and anticipated values are found to be consistent with the actual values. The values of $R^{2}$ for the maximum temperature are 0.9991 and 0.9888 for the simulated and anticipated values, respectively, which reveals the fact that the retrogression is eloquent, as indicated in Fig. 5a and b.

\subsection{Significance Test of the Predicted Model}

The significance test of the predicted model fit for maximum temperature was performed using Minitab tool based on ANOVA. The investigations were performed at a $5 \%$ level of significance and for a confidence level of 95 percent. The ANOVA outcomes for the predicted peak temperature are mentioned 
Table 5. Results of the experimental run design matrix

\begin{tabular}{|c|c|c|c|c|c|c|}
\hline \multirow{2}{*}{ Runs } & \multirow{2}{*}{$\begin{array}{l}\text { Force in axial upward } \\
\text { direction [kN] }\end{array}$} & \multirow{2}{*}{$\begin{array}{c}\text { Speed of tool } \\
\text { traverse }[\mathrm{mm} / \mathrm{min}]\end{array}$} & \multirow{2}{*}{$\begin{array}{l}\text { Speed of tool } \\
\text { rotation [rpm] }\end{array}$} & \multicolumn{3}{|c|}{ Max. temperature $\left[{ }^{\circ} \mathrm{C}\right]$} \\
\hline & & & & Experi-mental & Predicted & FEA Simu-lated \\
\hline 1 & 5 & 1.75 & 1000 & 415 & 411.17 & 424.89 \\
\hline 2 & 3 & 3 & 750 & 220 & 224.31 & 225.91 \\
\hline 3 & 3 & 0.5 & 500 & 267 & 278.94 & 273.14 \\
\hline 4 & 5 & 0.5 & 500 & 373 & 360.44 & 383.12 \\
\hline 5 & 3 & 0.5 & 750 & 360 & 350.36 & 367.46 \\
\hline 6 & 4 & 1.75 & 750 & 325 & 321.33 & 331.24 \\
\hline 7 & 4 & 1.75 & 1000 & 383 & 371.33 & 391.49 \\
\hline 8 & 3 & 1.75 & 500 & 186 & 189.50 & 192.91 \\
\hline 9 & 3 & 1.75 & 750 & 257 & 268.33 & 263.33 \\
\hline 10 & 5 & 1.75 & 750 & 368 & 361.33 & 381.39 \\
\hline 11 & 5 & 3 & 750 & 331 & 329.14 & 337.89 \\
\hline 12 & 5 & 0.5 & 750 & 429 & 431.53 & 440.96 \\
\hline 13 & 4 & 0.5 & 750 & 398 & 397.44 & 409.74 \\
\hline 14 & 4 & 1.75 & 750 & 323 & 321.33 & 331.24 \\
\hline 15 & 3 & 0.5 & 1000 & 401 & 393.11 & 409.74 \\
\hline 16 & 3 & 3 & 1000 & 273 & 281.89 & 282.36 \\
\hline 17 & 4 & 3 & 1000 & 343 & 340.64 & 355.64 \\
\hline 18 & 5 & 1.75 & 500 & 277 & 282.83 & 286.08 \\
\hline 19 & 5 & 3 & 1000 & 390 & 386.39 & 398.74 \\
\hline 20 & 4 & 0.5 & 500 & 331 & 326.19 & 342.81 \\
\hline 21 & 4 & 0.5 & 1000 & 433 & 440.03 & 449.63 \\
\hline 22 & 4 & 1.75 & 750 & 322 & 321.33 & 331.24 \\
\hline 23 & 4 & 3 & 500 & 197 & 197.14 & 206.41 \\
\hline 24 & 4 & 1.75 & 500 & 231 & 242.67 & 240.44 \\
\hline 25 & 4 & 3 & 750 & 273 & 283.22 & 282.36 \\
\hline 26 & 3 & 1.75 & 1000 & 319 & 318.50 & 331.24 \\
\hline 27 & 3 & 3 & 500 & 163 & 158.06 & 165.89 \\
\hline 28 & 4 & 1.75 & 750 & 325 & 321.33 & 331.24 \\
\hline 29 & 5 & 3 & 500 & 237 & 243.22 & 244.96 \\
\hline 30 & 5 & 0.5 & 1000 & 460 & 473.94 & 477.91 \\
\hline
\end{tabular}

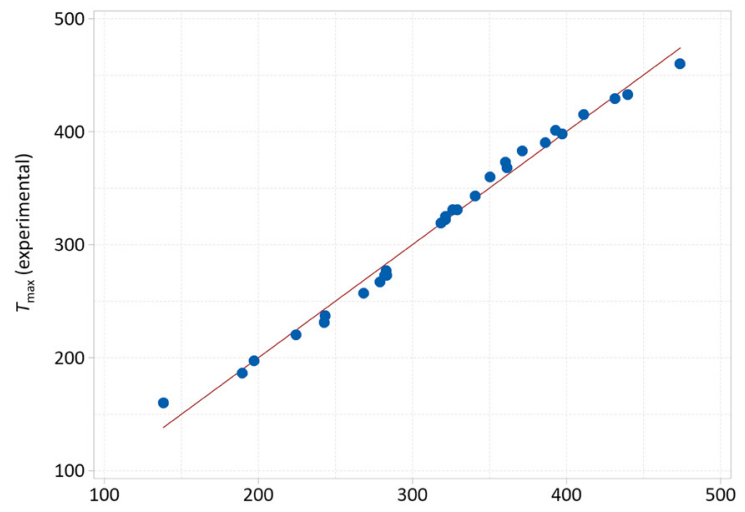

a)

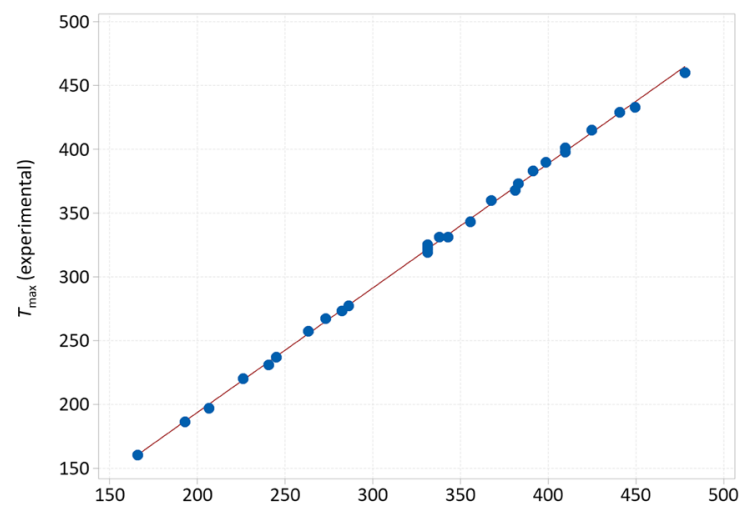

b)

$T_{\max }$ (FEA simulated)

Fig. 5. Relationship between a) anticipated and experimental $T_{\text {max }}$; and b) FEA simulated and experimental $T_{\max }$ 
Table 6. ANOVA results for peak temperature

\begin{tabular}{lccccccc}
\hline Source & Degree of Freedom & Seq SS & Contribution [\%] & Adj MS & Adj SS & P-value & F-value \\
\hline Effigy & 9 & 176865 & 98.88 & 19651.7 & 176865 & 0.000 & 195.54 \\
\hline Linear & 3 & 172129 & 96.23 & 57376.2 & 172129 & 0.000 & 570.92 \\
\hline Speed & 1 & 74498 & 41.65 & 74498.0 & 74498 & 0.000 & 741.29 \\
\hline Force & 1 & 38920 & 21.76 & 38920.5 & 38920 & 0.000 & 387.28 \\
\hline Feed & 1 & 58710 & 32.82 & 58710.2 & 58710 & 0.000 & 584.20 \\
\hline Square & 3 & 3656 & 2.04 & 1218.7 & 3656 & 0.000 & 12.13 \\
\hline Speed $\times$ Speed & 1 & 1080 & 0.60 & 1408.8 & 1409 & 0.001 & 14.02 \\
\hline Force $\times$ Force & 1 & 100 & 0.06 & 289.7 & 290 & 0.105 & 2.88 \\
\hline Feed $\times$ Feed & 1 & 2475 & 1.38 & 2475.4 & 2475 & 0.000 & 24.63 \\
\hline 2-Way interaction & 3 & 1081 & 0.60 & 360.2 & 1081 & 0.032 & 0.955 \\
\hline Speed $\times$ Force & 1 & 0 & 0.0002 & 0.3 & 0 & 0.019 & 0.00 \\
\hline Speed $\times$ Feed & 1 & 660 & 0.37 & 660.1 & 660 & 6.57 \\
\hline Force $\times$ Feed & 1 & 420 & 0.23 & 420.1 & 420 & 0.054 & 4.18 \\
\hline Error & 20 & 2010 & 1.12 & 100.5 & 2010 & & 5.004 \\
\hline Lack-of-Fit & 17 & 2003 & 1.12 & 117.8 & 2003 & & 52.37 \\
\hline Pure error & 3 & 7 & 0.00 & 2.3 & 7 & & \\
\hline Total & 29 & 178875 & 100.00 & & &
\end{tabular}

in Table 6 from which it can be observed that the developed model is perfectly ideal, as the value of $F$ is quite larger and $P r o b>F$ value is lower by 0.05 .

Apart from this, it can also be visualized from this table that the linear contributions by the input process parameters of FSW namely, traversing speed, rotating tool speed and axial force on the peak temperature are $32.82 \%, 41.65 \%$, and $21.76 \%$, respectively. Likewise, the square percentage contributions of these input parameters, namely, traversing speed, axial force and rotational speed on the peak temperature are $1.38 \%, 0.06 \%$, and $0.60 \%$, respectively. These values reveal that the input parameter (i.e., the tool traversing speed) has a dominant part in influencing the peak temperature, during the joining of AZ80A Mg alloy.

\subsection{Finite Element Temperature Distribution}

The predicted $T_{\max }$ was verified with the observed temperature and was proved to agree with it perfectly. The optimized experimental conditions (rotational speed $=818 \mathrm{rpm}$; axial force $=3.646 \mathrm{kN}$; traversing speed of FSW tool $=1.48 \mathrm{~mm} / \mathrm{s}$ ) specified by Sevvel et al. [23] were taken into account for generating and drafting the line plots and contours. The variations of temperature in workpiece on the bonding line and the offset lines when the tool reaches mid of the work piece are shown in Fig. 6. The experimental outcomes are also compared with the FEA simulated values and included in this Fig. 6.

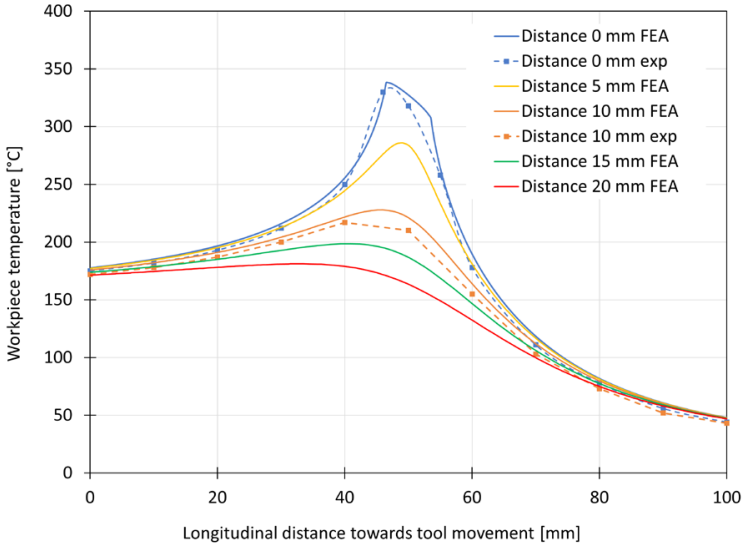

Fig. 6. Temperature variation along the longitudinal axis and its offset

The comparisons aid in understanding that the FEA numerical results of the temperature values perfectly coincide with that of the experimental data. Also, the variations of the temperature in the workpiece transverse axis behind and in front of the tool movement were illustrated in Figs. 7a and 7b, respectively.

It can be easily visualized from Fig. 8a and $\mathrm{b}$ that during the joining of AZ80A Mg alloy by FSW, the maximum value of temperature lies within the regions of workpiece contacted by the rotating FSW tool shoulder and is around $368{ }^{\circ} \mathrm{C}$, which is nearly $70 \%$ to $72 \%$ of the melting point $\left(490{ }^{\circ} \mathrm{C}\right)$ of the parent metal. 


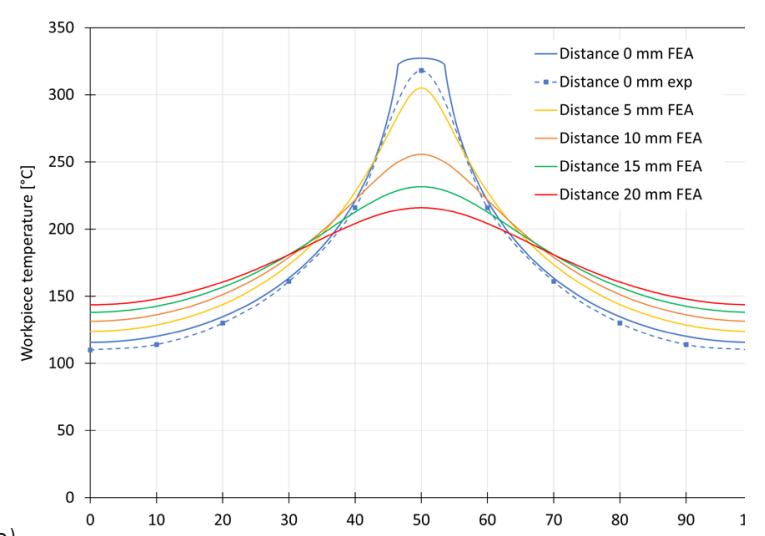

a)

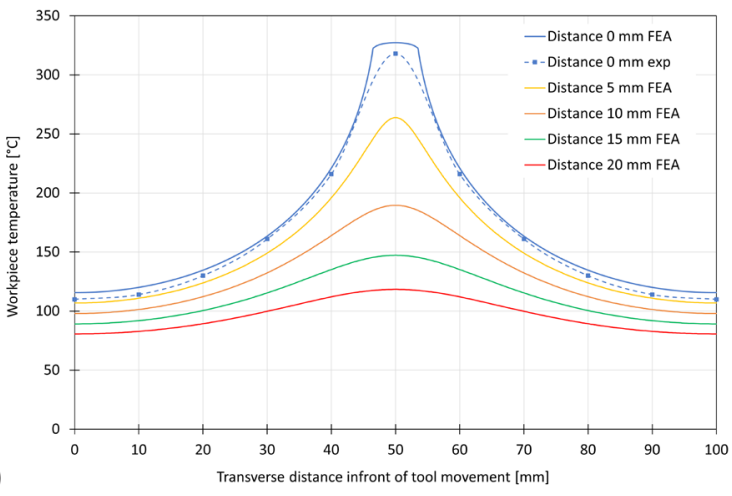

Fig. 7. a) Temperature variation along the transverse axis a) behind tool movement and its offset, and b) in front of tool movement and its offset

The experimental results confirm that the FSW of $\mathrm{Mg}$ alloys (especially AZ80A Mg alloy) is a solidstate joining process and, during the fabrication of this $\mathrm{Mg}$ alloy joints, bonding has occurred perfectly, thereby resulting in sound quality welds.

\subsection{Experimental Verification Using Optimized Values}

Fig. 9 shows the optical micrographs of the parent metal and various regions of the defect-free AZ80 $\mathrm{Mg}$ alloy FSW joints obtained during the employment of the optimized process parameters. From these optical micrographs, it can be visualized that the microstructure of the cast parent metal (AZ80A Mg alloy) consists of a dendritic network, with the cored grains of $\mathrm{mg}$ solid solution with large precipitates of Mg17Al12 particles at the grain boundaries, as shown in Fig. 9a. Fig. 9b portrays the region of the interface at the side of tool advancement. In this image, the left side shows the microstructure of the base metal, and the right side shows the zone of the nugget. This aids in perceiving that the impact of temperature and the stress has resulted in the uniform flow of zone of fusion along with the appearance of fragmented particles that have been recrystallized.

The thermo-mechanically transformed region along with the constituents of the parent metals can be seen in Fig. 9c. This figure helps us to understand the orientation of grains from both the sides of the parent metal has taken place due to the impact of the peak temperature generated in the region of contact of the workpiece (i.e., the FSW tool shoulder surface) thereby resulting in the fusion of the constituents of the parent metal on both sides of the joint.

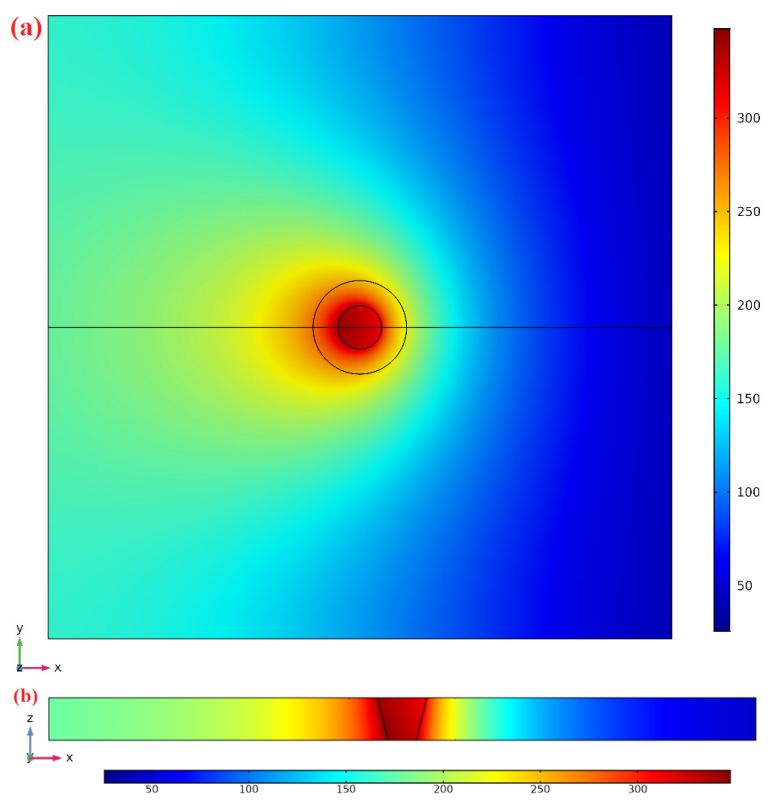

Fig. 8. Temperature contour; a) obtained from FEA results for optimized condition, and b) on bonding surface for optimised condition (rotational speed $=818 \mathrm{rpm}$; axial force $=3.646 \mathrm{kN}$; traversing speed of FSW tool $=1.48 \mathrm{~mm} / \mathrm{s}$ )

We can also observe that the various surface regions of the parent metal closer to the contact point of the FSW tool shoulder region also have experienced a reasonable amount of heat generation and rise in temperature, which has led to the formation of alternate layers, as seen in the Fig. 9d, due to the marginal flow of plasticized material influenced by the stirring action by FSW tool shoulder.

The impact of the peak temperature obtained during the joining of flat plates of AZ80A Mg alloy can be observed clearlyfrom Fig. 9e, which portrays us the partial evaporation of the constituents (mainly Zinc) from both the sides of the parent metal surfaces, which have been under the direct contact with the rotational shoulder of the FSW tool. Apart from this, we can infer that the FSW process also plays a very important role in improvising and enhancing 
the microstructural characteristics of the magnesium alloys (especially AZ80A Mg alloy). This is evident from Fig. 9f, which shows the presence of fine fragmented grain particles, which have been spaced in a uniformly distributed homogeneous manner, when compared with the large, uneven, and coarse grains in the parent metal. This complete transformation of grain structure has occurred mainly due to the generation of ideal peak temperature resulting in super plasticity, uniform flow of the plasticized metal along with dynamic recrystallization.
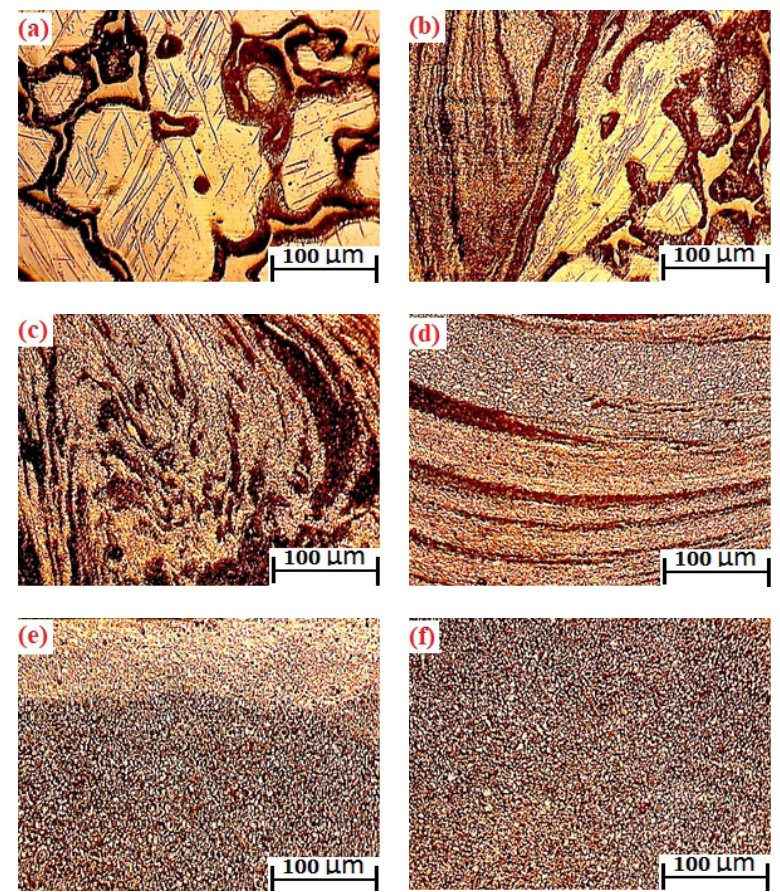

Fig. 9. Optical micrographs of; a) parent metal, b) region of interface at side of tool advancement, c) thermo-mechanically transformed region along with the constituents of the parent metal, d) regions of the parent metal closer to the contact point of the FSW tool shoulder region, e) shoulder influenced region with partial evaporation of constituents of base metal, and f) nugget zone of the defect-free AZ80 Mg alloy FSW joint obtained during

the employment of the optimized process parameters

To add additional weight to the inferred result of the complete transformation of grain structure due to the generation of the ideal peak temperature, the SEM image of AZ80A Mg alloy is shown in the Fig. 10a, which illustrates the presence of course, unevenly distributed with massive precipitates of $\mathrm{Mg}_{17} \mathrm{Al}_{12}$ particles at the grain boundaries. Fig. 10b portrays the interface region of the parent metal with the stir zone.

This SEM image helps us understand that, at the interface region, the grains have been fragmented and, at the stir region, the constituents of the AZ80A Mg
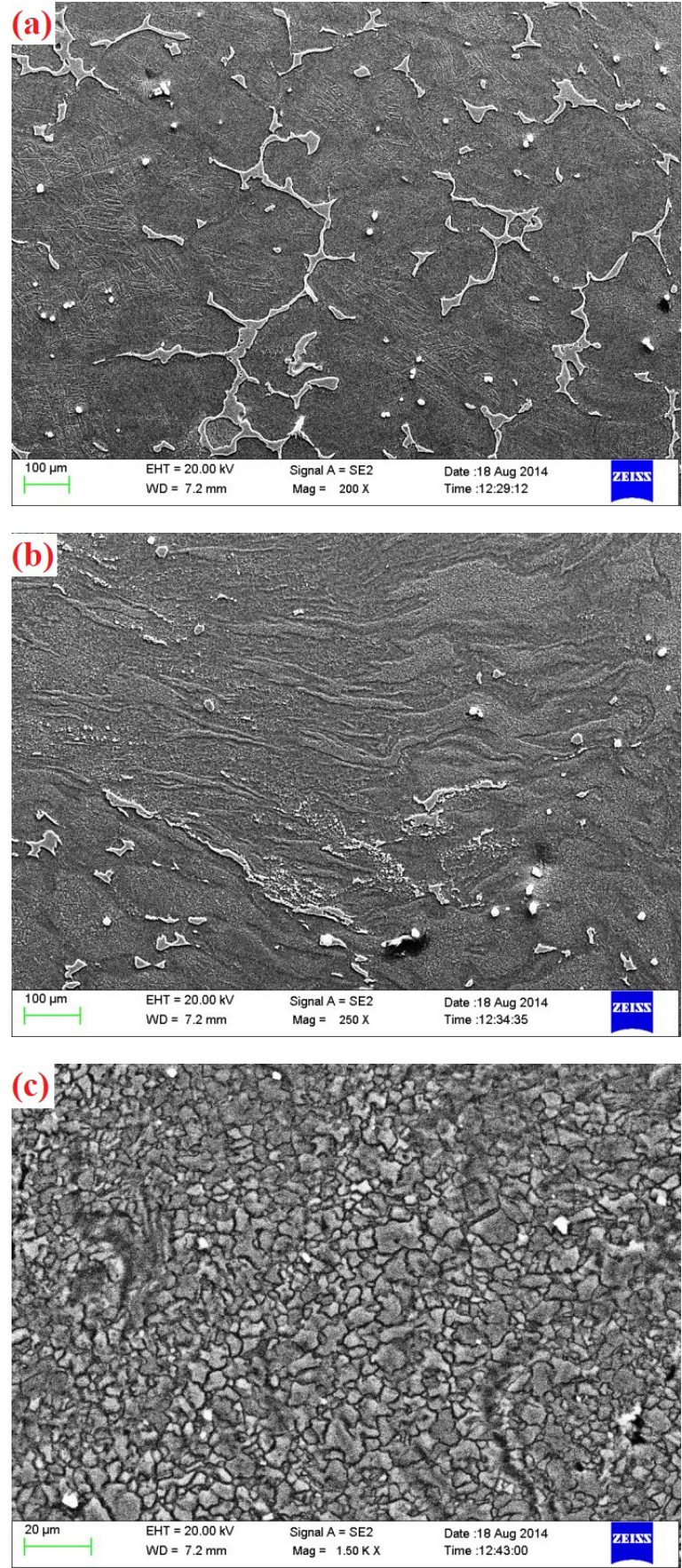

Fig. 10. SEM images of the; a) parent metal, b) interface junction of the parent metal AZ80A Mg alloy with the stir zone, and c) centre of stir zone at $1000 \times$ magnification

alloy have been completely dissolved, and the grains have been fragmented due to dynamic recrystallization. Fig.10c shows the magnified SEM image of the stir zone obtained at $1000 \times$ magnification. In this image, we can see the secondary phase particles of 
the AZ80A Mg alloy has been completely dissolved, which occurred due to the generation of ideal peak temperature resulting from the adoption of optimized process parameters.

\subsection{Influence of Process Parameters}

As it has been proved by several researchers [24] to [26] that the rotational speed of tool, its speed of traverse, and the load applied to it are some of the influencing parameters of an FSW process, in this experimental and numerical investigation, the influential role of those three process parameters on the peak temperature was analysed by simulating their impact during the impact on heat generation during the FSW of the parent metal, by employing the proposed FEA analysis model and are illustrated in the Fig. 11. From Fig. 11a, it can be inferred that the peak temperature escalates with the upsurge of the speed of rotation of the FSW tool and declines with the rise in the FSW tool's traversing speed.

However, at the same time, from Fig. 11b, it can be interpreted that at the fixed tool traversing speed, with the simultaneous increase in the speed of rotation of FSW tool and axial load, the peak temperature rises. Moreover, at the fixed rotational speed of the FSW tool, the peak temperature escalates with the upsurge of the axial force and declines with the rise in the FSW tool's traversing speed, as shown in Fig. 11c.

Based on the careful observation of these simulated temperature contour graphs, we can infer that performing the joining of AZ80A Mg alloys by FSW, at an optimized combination of higher rotational speeds of FSW tool, with the FSW tool traversing at low speeds and by applying larger values of the axial load results in the generation of ideal peak temperature, which eventually contributes to perfect bonding between the AZ80A Mg alloy plates to be welded, thereby resulting in sound quality weldments.

\section{CONCLUSIONS}

In the present experimental research, an investigational analysis during the joining of AZ80A $\mathrm{Mg}$ alloy was carried out to formulate a correlation to analysis generation of peak temperature. The A3 dimensional steady-state model for heat-transfer in a movable type coordinate was modelled and simulated to visualize the temperature distribution in the parent metal. In addition to this, detailed parametric studies were carried out to understand the influence of parameters of the FSW process in the generation of
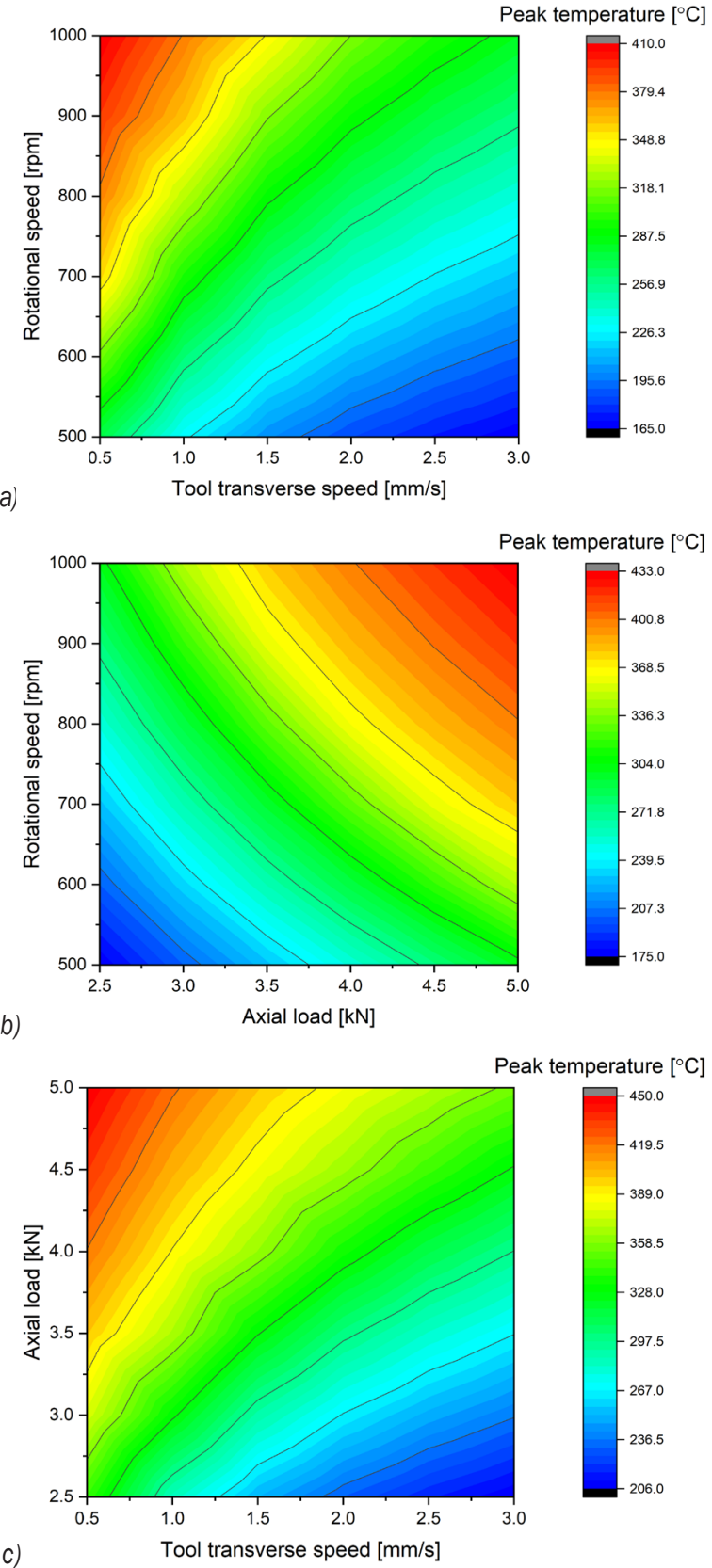

Fig. 11. Simulated temperature contour on the bonding surface for optimized condition; a) concerning the speed of rotation of FSW tool and its traversing speed for fixed axial load, b) concerning the speed of rotation of FSW tool and axial load for fixed tool traversing speed, and c) concerning tool traversing speed and axial load at fixed speed of rotation of FSW tool

peak temperature and the following inference were derived:

- The formulated correlation for $T_{\max }$ was able to accurately predict the maximum temperature generation during the FSW of flat plates of 
AZ80A Mg alloy. The predicted $T_{\max }$ was verified with the observed temperature and was proved to agree perfectly.

- Variations between the predicted correlation and the obtained actual values and the simulated FEA values were found to be comparably small. The simulated and anticipated values are found to be consistent with the actual values. The values of $R^{2}$ for the maximum temperature are 0.9991 and 0.9888 for the simulated and anticipated values, respectively.

- Linear contributions by the input process parameters of FSW namely, traversing speed, rotating tool speed and axial force on the peak temperature were observed to be $32.82 \%$, $41.65 \%$ and $21.76 \%$, respectively. Likewise, square percentage contributions of these input parameters, namely, traversing speed, rotating tool speed and axial force on the peak temperature are $1.38 \%, 0.60 \%$, and $0.06 \%$, respectively.

- The experimental and predicted values reveal that the input parameter (i.e., the tool traversing speed) has an important part in influencing the peak temperature during the joining of AZ80A Mg alloy.

- The significance test of the predicted model fit for maximum temperature was performed using a Minitab tool based on ANOVA and it was observed that the developed model was perfectly ideal, as the value of $F$ was quite larger and Prob $>F$ value was lower by 0.05 .

- It was visualized from the generated temperature contour graphs that the maximum value of temperature lies within the regions of workpiece contacted by the rotating FSW tool shoulder and is around $368{ }^{\circ} \mathrm{C}$, which is nearly $70 \%$ to $72 \%$ of the melting point $\left(490{ }^{\circ} \mathrm{C}\right)$ of the parent metal.

- It was inferred that performing the FSW of AZ80A Mg alloys at an optimized combination of higher rotating tool speeds, with the FSW tool traversing at low speeds and by applying larger values of the axial load results in the generation of ideal peak temperature, which eventually contributes to perfect bonding between the AZ80A Mg alloy plates to be welded, thereby resulting in sound quality welds.

\section{REFERENCES}

[1] Zhou, L., Nakata, K., Liao, J., Tsumura, T. (2012) Microstructural characteristics and mechanical properties of non-combustive Mg-9Al-Zn-Ca magnesium alloy friction stir welded joints. Materials and Design, vol. 42, p.505-512, DOI:10.1016/j.matdes.2012.06.005.

[2] Rafiei, R., Ostovari Moghaddam, A., Hatami, M.R., Khodabakhshi, F., Abdolahzadeh, A., Shokuhfar, A. (2017) Microstructural characteristics and mechanical properties of the dissimilar friction-stir butt welds between an Al-Mg alloy and A316L stainless steel. The International Journal of Advanced Manufacturing Technology, vol. 90, p. 2785-2801, DOI:10.1007/s00170-016-9597-x.

[3] Mironov, S., Onuma, T., Sato, Y.S., Kokawa, H. (2015). Microstructure evolution during friction-stir welding of AZ31 magnesium alloy. Acta Materialia, vol. 100, p. 301-312, DOl:10.1016/J.msea.z2007.01.065.

[4] Sevvel, P., Jaiganesh, V. (2017). Influence of the arrangement of materials and microstructural analysis during FSW of AZ8OA \& AZ91C Mg alloy. Archives of Metallurgy and Materials, vol. 62, p. 1795-1801, D0l:10.1515/amm-2017-0272.

[5] Liu, Z., Liu, D., Xu, J., Zheng, X., Liu, Q., Xin, R. (2015). Microstructural investigation and mechanical properties of dissimilar friction stir welded magnesium alloys. Science and Technology of Welding and Joining, vol. 20, p. 264-270, DOl:10.1179/1362171815Y.0000000009.

[6] Li, G.H., Zhou, L., Luo, S.F., Dong, F.B., Guo, N. (2020). Quality improvement of bobbin tool friction stir welds in $\mathrm{Mg}$ Zn-Zr alloy by adjusting tool geometry. Journal of Materials Processing Technology, vol. 282, p. 116685, Dol:10.1016/j. jmatprotec.2020.116685.

[7] Yang, J., Ni, D.R., Xiao, B.L., Ma, Z.Y. (2014). Non-uniform deformation in a friction stir welded $\mathrm{Mg}-\mathrm{Al}-\mathrm{Zn}$ joint during stress fatigue. International Journal of Fatigue, vol. 59, p. 9-13, D0l:10.1016/j.jifatigue.2013.10.004.

[8] Sevvel, P., Jaiganesh, V. (2017). Investigation on evolution of microstructures and characterization during FSW of AZ8OA Mg alloy. Archives of Metallurgy and Materials, vol. 62, no. 17791785, DOl:10.1515/amm-2017-0270.

[9] Liu, D., Xin, R., Li, Z., Liu, Z., Zheng, X., Liu, Q. (2015). The activation of twinning and texture evolution during bending of friction stir welded magnesium alloys. Material Science and Engineering: A, vol. 646, p. 145-153, D0l:10.1016/j. msea.2015. 08.059.

[10] Xie, X., Shen, J., Cheng, L., Li, Y., Pu, Y. (2015). Effects of nanoparticles strengthening activating flux on the microstructures and mechanical properties of TIG welded AZ31 magnesium alloy joints. Materials \& Design, vol. 81, p. 31-38, DOI:10.1016/j.matdes.2015.05.024.

[11] Liu, D., Xin, R., Hongni, Y., Liu, Z., Zheng, X., Liu, Q. (2016). Comparative examinations on the activity and variant selection of twinning during tension and compression of magnesium alloys. Material Science and Engineering: A, vol. 658, p. 229237, DOI:10.1016/J.msea.2016.01.098.

[12] Qian, J., Ou, Y., Li, J., Xiao, Y., Wu, L., Xu, Y. (2017). An analytical model to calculate the peak temperature for friction stir welding. Science and Technology of Welding and Joining, vol. 22, no. 6, p. 520-525, Dol:10.1080/13621718.2016.126 8367.

[13] Arbegast, W.J. (2008). A flow-partitioned deformation zone model for defect formation during friction stir welding. 
Scripta Materialia, vol. 58, no. 5, p. 372-376, D0l:10.1016/j. scriptamat.2007.10.031.

[14] Padmanaban, R., Ratna Kishore, V., Balusamy, V. (2014). Numerical simulation of temperature distribution and material flow during friction stir welding of dissimilar aluminum alloys. Procedia Engineering, vol. 97, p. 854-863, D0l:10.1016/j. proeng.2014.12.360.

[15] Song, M., Kovacevic, R. (2003). Thermal modelingof friction stir welding in a moving coordinate system and its validation. International Journal of Machine Tools and Manufacture, vol. 43, no. 6, p. 605-615, D0l:10.1016/S0890-6955(03)00022-1.

[16] Chao, Y.J., Qi, X., Tang, W. (2003). Heat transfer in friction stir welding-experimental and numerical studies. Journal of Manufacturing Science and Engineering, vol. 125, no. 1, p. 138-145, Dol:10.1115/1.1537741.

[17] Gok, K., Aydin, M. (2013). Investigations of friction stir welding process using finite element method. International Journal of Advanced Manufacturing Technology, vol. 68, p. 775-780, DOl:10.1007/s00170-013-4798-z.

[18] Chen, C.M., Kovacevic, R. (2003). Finite element modeling of friction stir welding-thermal and thermo mechanical analysis. International Journal of Machine Tools and Manufacture, vol. 43, no. 13, p. 1319-1326, D0l:10.1016/S08906955(03)00158-5.

[19] Mohammad, R., Hamidreza, N. (2011). Analysis of transient temperature and residual thermal stresses in friction stir welding of aluminium alloy 6061-T6 via numerical simulation. International Journal of Advanced Manufacturing Technology, vol. 55, p. 143-152, D0l:10.1007/s00170-010-3038-z.

[20] Li, W.Y., Zhang, Z.H., Li, J.L. (2012). Numerical analysis of joint temperature evolution during friction stir welding based on sticking contact. Journal of Materials Engineering and
Performance, vol. 21, p. 1849-1856, Dol:10.1007/s11665011-0092-0.

[21] Hasan, A., Bennett, C.J., Shipway, P.H. (2015). A numerical comparison of the flow behaviour in friction stir welding (FSW) using unworn and worn tool geometries. Materials \& Design, vol. 87, p. 1037-1046, D0I:10.1016/j.matdes. 2015.08.016.

[22] Nandan, R., Roy, G.G., Debroy. T. (2006). Numerical simulation of three-dimensional heat transfer and plastic flow during friction stir welding. Metallurgical and Materials Transactions A, vol. 37, p. 1247-1259, D0l:10.1007/s11661-006-1076-9.

[23] Sevvel, P., Satheesh, C., Senthil Kumar, R. (2019). Generation of regression models and multi response optimization of friction stir welding technique parameters during fabrication of AZ80A Mg alloy joints. Transactions of the Canadian Society for Mechanical Engineering, vol. 44, no. 2, p. 311-324, DOI:10.1139/tcsme-2019-0162.

[24] Malopheyev, S., Vysotskiy, I., Kulitskiy, V., Mironov, S., Kaibyshev, R. (2016). Optimization of processingmicrostructure-properties relationship in friction-stir welded 6061-T6 aluminum alloy. Material Science and Engineering: $A$, vol. 662, p. 136-143, D0l:10.1016/j.msea.2016.03.063.

[25] Liu,X., Chen, G., Ni,J., Feng, Z. (2017). Computational fluid dynamics modeling on steady-state friction stir welding of aluminum alloy 6061 to TRIP steel. Journal of Manufacturing Science and Engineering, vol. 139, no. 5, art. ID 051004, DOI:10.1115/1.4034895.

[26] Wang, W., Deng, D., Mao, Z., Tong, Y., Ran, Y. (2017). Influence of tool rotation rates on temperature profiles and mechanical properties of friction stir welded AZ31 magnesium alloy. International Journal of Advanced Manufacturing Technology, vol. 88, p. 2191-2200, D0l:10.1007/s00170-016-8918-4. 